Eeva-Liisa Maunuksela MD, Klaus T. Olkkola MD, Reijo Korpela MD

\title{
Does prophylactic intravenous infusion of indomethacin improve the management of postoperative pain in children?
}

The efficacy of prophylactic intravenous infusion of indomethacin as a postoperative analgesic was studied in 100 children aged one to 16 years. At the end of surgery a bolus dose of indomethacin $0.35 \mathrm{mg} \cdot \mathrm{kg}^{-1}$ followed by an infusion 0.07 $m g \cdot \mathrm{kg}^{-1} \cdot \mathrm{hr}^{-1}$ for $24 \mathrm{hr}$ ar placebo was given in double-blind manner. The efficacy of the treatment was measured by the need of additional morphine given $0.1 \mathrm{mg} \cdot \mathrm{kg}^{-1}$ intravenously in the Recovery Room and $0.15 \mathrm{mg} \cdot \mathrm{kg}^{-1}$ inramuscularly on the ward according to clinical needs. The other measure of the efficacy was assessment of pain inlensity in the Recovery Room and pain relief on the ward. In the Recovery Room the pain scores differed between the groups in advantage of indomethacin anly at 30 minutes ( $p<0.05$ ) but the need of morphine wias significantly Less $(p<0.01)$ in the indomethacin group. On the ward the mean doses of morphine given and the nurses' pain relief scores were not different between the study groups. However. in the indomethacin group the total dose of morphine given during $24 \mathrm{hr}$ was lower $(p=0.02)$ and the children assessed the pain relief to be significantly better $(p<0.02)$. Twenty per cent of the children in both groups had transient nausea and vomiting. No skin reactions or other aliergic manifestations were observed. Prophylactic indomethacin infusion diminished the need of morphine and resulted in betler postoperative analgesia than morphine p.r.n. alone.

\section{Key words}

PAIN: postoperative, treatment; ANALGESIC: indomethacin; sURGERY: paediatric.

From The Children's Hospital and Department of Clinical Pharmacology, University of Helsinki, Helsinski, Figland.

Address correspondence to: Dr. Eeva-Liisa Maunuksela, Department of Anesthesiology, University of Helsinki, 00290 Helsinki, Finland.

This study was supported by a grant from the Paulo Foundation.

Presented in part at the 1987 mccting of the International Association for the Study of Pain, Hamburg, FRG.
Although postoperative pain can be anticipated, its therapy is often neglected. This undermedication is even more pronouned in children. ${ }^{1,2}$ This might be due to the limited research providing only a few guidelines for the management of pain in children. In the absence of sound knowledge the clinical practice is based on many myths about children's pain and their exceptional sensitivity to analgesics.

The child does not usually request pain medication. Therefore the major route to knowledge of pain in children is the study of their behaviour. The child's reaction to pain is dependent on his developmental stage. In all age groups the child reacts with regression and withdrawal, ${ }^{3}$ which is often misinterpreted as coping well with the pain. These are some of the reasons why the "when needed"-prescription does not result in satisfactory analgesic therapy in pediatric paractice. ${ }^{4} \mathrm{~A}$ solution to this problem could be a prophylactic continuous analgesic infusion.

As a non-steroidal anti-inflammatory drug indomethacin has a potent analgesic effect. ${ }^{5}$ Since the 1960 's it has become one of the most commonly used therapeutic agents in juvenile theumatoid arthritis and there are reports of its use in the treatment of pericarditis in children. ${ }^{6}$ Intravenous indomethacin is used for closure of patent ductus arteriosus in preterm infants. ${ }^{7,8}$ However, to our knowledge it has not been evaluated as a postoperative analgesic for children. To test the efficacy and tolerance of intravenous indomethacin we performed a double-blind study on 100 operated children.

\section{Methods}

A total of 100 , one- to 16-year-old boys and girls, ASA physical status class I or II, participated in the study. The study protocol was accepted by the ethical committee of the Children's Hospital, University of Helsinki, and informed consent was obtained. A double blind non-cross over study design was used. The children were scheduled for orthopaedic or general surgical procedures known to 
usually require postoperative analgesic therapy. Children having mental retardation, muscular dystrophies or paresthesias, abnormal liver or kidney function, bronchial asthma or sensitivity to acetylsalicylic acid or other anti-inflammatory agents were excluded from the study.

\section{Premedication and anaesthesia}

The same premedication and anaesthetic technique was used for all patients. Oral or rectal flunitrazepam was given for premedication $0.1 \mathrm{mg} \cdot \mathrm{kg}^{-1}$ (maximum $2 \mathrm{mg}$ ) and rectal methohexitone $10-15 \mathrm{mg} \cdot \mathrm{kg}^{-1}$ to small children if necessary. Anaesthesia was induced with thiopentone 2-5 $\mathrm{mg} \cdot \mathrm{kg}^{-1}$ preceded by an intravenous (IV) anticholinergic agent. Intubation was facilitated with 1.0-1.5 $\mathrm{mg} \cdot \mathrm{kg}^{-1}$ of succinylcholine. For maintenance of anaesthesia nitrous oxide/oxygen (2:1) and enflurane or halothane were used. If needed the muscle relaxation was achieved with a nondepolarizing muscle relaxant and the degree of neuromuscular blockade was monitored with a transcutaneous nerve stimulator. At the end of surgery the rcsidual ncuromuscular blockade was reversed with standard doses of neostigmine and an anticholinergic agent. The patients were extubated and transferred to the Recovery Room. No analgesics were given during anaesthesia.

\section{Study drug and analgesic therapy}

The indomethacin (Confortid ${ }^{\circledR}$, Dumex Lid., Denmark) and placebo solutions were prepared according to a randomization list. The bolus dose of $0.35 \mathrm{mg} \cdot \mathrm{kg}^{-1}$ indomethacin or placebo was a 5 or $10 \mathrm{ml}$ injection, which was given during 15 min at the end of surgery. The continuous infusions $0.07 \mathrm{mg} \cdot \mathrm{kg}^{-1} \cdot \mathrm{hr}^{-1}$ of indomethacin or placebo were prepared in a $50 \mathrm{ml}$ IVAC syringe nun by an IVAC 700 (IVAC Co., California, U.S.A.) perfusor at a rate of $2.0 \mathrm{ml} \cdot \mathrm{hr}^{-1}$. To maintain the double-blind conditions the indomethacin and placebo solutions were prepared to have similar appearance. ${ }^{9}$ In both study groups additional morphine was given for postoperative pain 0.1 $\mathrm{mg} \cdot \mathrm{kg}^{-1} \mathrm{I} . \mathrm{V}$. in the recovery room and $0.15 \mathrm{mg} \cdot \mathrm{kg}^{-1} \mathrm{IM}$ on the ward according to clinical needs. No other analgesics were used.

\section{Sudy procedure and records}

The assessment of the patient was made by a member of the study group or by a trained research nurse. The patients were observed for two hours in the Recovery Room. Pain intensity and sedation scores together with cardioventilatory parameters were measured/assessed every 15 minutes. The pain intensity was scored: $0=$ no pain, $1-3=$ slight pain, $4-5=$ moderate pain, $6-8=$ severe pain, and $9=$ worst possible pain. This scale is based on mimic, vocalization, movements or rigidity of the limbs and body, response to handling, and irritability together with the measured cardioventilatory parameters. The separate items were not scorcd according to a fixcd scale. However, when the observer judged the general pain intensity, all the items were taken into consideration and related to the situation of the patient. The same observer continuously assessed the child. Thus the assessments were in relation to each other, although the pain intensity scale was subjective for the observer ${ }^{10}$ Correspondingly, sedation was scored from 0 to $4(0=$ fully awake, 1 = slightly drowsy, 2 = asleep but easily arousable, $3=$ fully asleep but arousable, and $4=$ asleep, not arousable). Thereafter the child was asked about his pain. The answer was recorded as verbal pain intensity: 0 = no pain, 1 = hurting a little, 2 = moderate pain, $3=$ severe pain. When the patient complained of pain or was assessed to have moderate to severe pain, an IV dose of morphine was given at 5-15 min intervals until he was completely free of pain.

Following the two hour recovery period the patients were transferred to the surgical ward with the continuous study drug infusion. The children were cared for in a routine manner by paediatric surgical nurses of the ward. If additional analgesic was needed the standard dose of IM morphine was given. Analgesic, antipyretic and other medication, together with unwanted effects were recorded for $24 \mathrm{hr}$ postoperatively. At the end of every shift the nurse assessed the efficacy of the analgesic therapy. Pain relief was scored as $1=$ very good, $2=\operatorname{good}, 3=$ fair, $4=$ poor or $5=$ very poor. If the answer was poor or very poor the reason was stated (insufficient effect, unwanted effects, other).

In the moming of the first postoperative day the anaesthetist asked the patient about the analgesic medication using the same 5-point scale. If the therapy was scored poor or very poor the reason for the statement was asked (insufficient effect, too short effect, unwanted effects or other reasons).

\section{Statistical analysis}

Student's t test for unpaired values and the chi-square test were used for the statistical analysis of the data. A p-value of 0.05 was considered as the limit of statistical significance.

\section{Results}

The demographic data of the patients is shown in Table I. The duration and type of operations were similar in both study groups. In the recovery room the mean ( $\pm \mathrm{SD}$ ) sedation scores decreased from $3.5 \pm 0.8$ to $2.3 \pm 1.1$ and from $3.4 \pm 1.1$ to $2.5 \pm 1.2$ in the indomethacin and placebo groups, respectively. The mean sedation scores did not differ significanty between the groups at any 


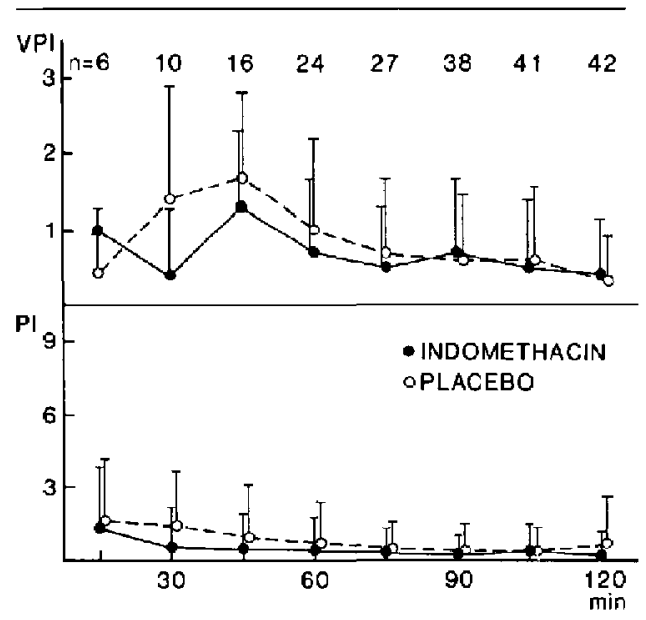

FIGURE I Mean ( \pm SD) verbal pain intensity (VPI) assessed by the children and pain intensity (PI) assessed by the observer during the first two hours in the recovery room. VPI-scale 0-3, PJ-scale 0-9. $N$ refers to the number of VPI assessments.

point. Although the mean pain intensity scores of the indomethacin group were slightly lower than those of the placebo group the difference was statistically significant ( $p<0.05$ ) only at 30 minutes (Figure 1). The number of verbal answers at any measuring point was low and the mean values of the verbal pain intensity did not differ statistically. There were some young patients unable to respond verbally in this situation. Most of the children not answering were asleep.

The mean doses of additional morphine given to the study groups are shown in Table II. Patients in the indomethacin group needed significantly less additional morphine in the Recovery Room. On the ward 24/51 and $18 / 49$ children in the indomethacin and placebo groups, respectively, did not receive any further dose of morphine during the $24 \mathrm{hr}$ study period. The mean ( \pm SD) values, of IM morphine given, $127 \pm 166$ and $165 \pm 171 \mu \mathrm{g} \cdot \mathrm{kg}^{-1}$ in

TABLE I Characteristics of the study groups (mean \pm SD)

\begin{tabular}{lcc}
\hline & $\begin{array}{l}\text { Indontethacin } \\
n=5 /\end{array}$ & $\begin{array}{l}\text { Placebe } \\
n=49\end{array}$ \\
\hline Buys/girls & $30 / 21$ & $33 / 16$ \\
Age, yrs & $7.0 \pm 5.1$ & $6.1 \pm 4.3$ \\
Weight, $\mathrm{kg}$ & $25.3=17.3$ & $22.9 \pm 15.5$ \\
Height, cm & $117 \pm 31$ & $114 \pm 27$ \\
$\begin{array}{l}\text { Operation: } \\
\text { Onthopaedic/general surgery }\end{array}$ & $31 / 20$ & $24 / 25$ \\
Duration, hours & $1.09 \pm 0.94$ & $0.85 \pm 0.61$ \\
\hline
\end{tabular}

$\mathrm{p}=\mathrm{NS}$.
TABLE II Administration of additional morphine (mean \pm SD) in the recovery room and during the first 24 hours in the two study groups

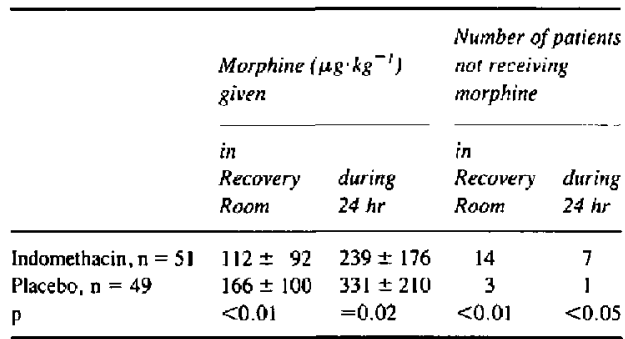

the indomethacin and placebo groups, respectively, did not differ. The total amount of morphine given during the $24 \mathrm{hr}$ study period was significantly less in the indomethacin group than in the placebo group. In the indomethacin group there were significantly more children who did not require any additional morphine in the Recovery Room (p<0.01) or during the first $24 \mathrm{hr}(\mathrm{p}<0.05)$.

On the ward the nurses evaluated the pain relief to be equal in both treatment groups. In the indomethacin and placebo groups 84 and 81 per cent of the scores were "good" or "very good." According to the nurses the pain relief was insufficient in ten per cent of the patients in the indomethacin group and in 18 per cent in the placebo group. Unwanted effects caused the score to be "poor" or "very poor" in 0 and 2 per cent and technical difficulties in six and two per cent respectively. There were no significant differences between the three shifts.

Assessment of the pain relief by the children is shown in Figure 2. Nine of the 100 children were not able to

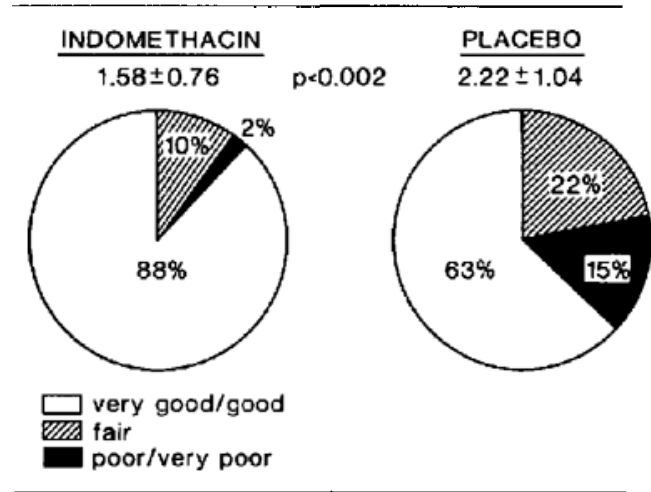

FIGURE 2 Assessment of the pain relief on the first postoperative morning by 91 of the children (nine children could not give their assessment because of age). Mean $\pm S D$ pain relief score $(?=$ very good $-5=$ very poor) and the percentage of different scores in the indomethacin and placebo groups. 
answer the questions because of their young age. The patients who had indomethacin infusion scored the pain relief to be significantly better. In the indomethacin group there was one child who considered pain relief poor whereas the corresponding number in the placebo group was nine.

The incidence of unwanted effects was low and did not differ between the two study groups. Ten palients in both groups had transient nausea and vomiting, threc patients in the indomethacin group vomited in the Recovery Room. In the placebo group two patients had difficulty voiding, one of them had to be catheterized. No skin reactions or other allergic manifestations were seen.

\section{Discussion}

A child usually does not request pain medication although he has learned to speak well. Children often have an exaggerated fear of injections and they even deny postoperative pain to avoid a needle. On a busy ward the nurse cannot observe every child closely enough to notice the signs of pain. This results in the common situation that even severe postoperative pain remains untreated. ${ }^{4}$ The nurses in our hospital appreciate a prescription for regular or continuous analgesic in order to avoid the often difficult decision of the severity of the child's pain. "

Despite the excellent analgesia that can be achieved by IV morphine infusion this method cannot be considered safe on wards. Narcotic analgesics are not suitable for prophylactic use in acute situations because of large interindividual variation in the responce. ${ }^{12,13}$

Non-steroidal anti-inflammatory drugs do not cause ventilatory depression and in the postoperative period an anti-inflammatory effect might be advantageous. Indomethacin given intravenously has been shown to be a useful postoperative analgesic in adults. ${ }^{5}$ In children it did not have any serious side effects. ${ }^{9}$

The intravenous route secures a fast and reliable analgesic effect and an cren level of analgesia as long as the child needs an infusion. The dose used in this study is derived from the usual adult IV dose and is in the median range compared with the doses used for juvenile theumatoid arthritis. Our clinical practice is to continue prophylactic analgesia with indomethacin syrup $3.0 \mathrm{mg} \cdot \mathrm{kg}^{-1} \cdot \mathrm{day}^{-1}$ as soon as oral intake is possible. According to our experience the incidence of gastrointestinal and central side effects in children is less than that reported in adult patients. ${ }^{9}$

The measurement of pain in children is a problem. Subjective assessment of pain should be primary always; whenever possible. However, there are situations, e.g., in the Recovery Room, Intensive Care Unit, or infant care, where skilled pain assessment by an experienced observer is valuable. The observer's ten-point pain intensity scale used in the present study has been shown to correlate well with the verbal comment of the child in all age groups, ${ }^{10}$ In the present study the children were brought to the Recovery Room asleep and they tended to fall asleep following intravenous morphine. Therefore the number of assessments of pain by the patient was only six out of 100 on arrival to the Recovery Room increasing to 42 out of 100 at $120 \mathrm{~min}$.

In the Recovery Room the patients were treated with additional IV morphine until free of pain. The pain scores tended to be lower and the use of morphine was significantly less in the indomethacin group compared with the placebo group. Twenty-seven per cent of the children in the indomethacin group were totally comfortable during the first $2 \mathrm{hr}$ without any additional morphine. This speaks for a notable acute analgesic effect of IV indomethacin compared with placebo.

On the ward $127 \pm 166$ and $165 \pm 171 \mathrm{mg} \cdot \mathrm{kg}^{-1}$ morphine was administered to the indomethacin and placebo group, respectively. This difference was not statistically significant. The nurses scored pain relief to be equal in both groups: good or very good in over 80 per cent of the given scores. This explains why a large proportion of children in both study groups did not receive any further analgesic on the ward.

Even when the nurses scored the pain relief to be poor, they did not - for some reason - give further injections of morphine. The allowed maximum dose of morphine, $0.15 \mathrm{mg} \cdot \mathrm{kg}^{-1}$ for cvery four hours, was never used. Apparently, the administration of morphine was not dependent only on the level of pain. This is in good agreement with previous studies. The nurses'decisions to medicate children are influenced by their education and several other factors in their back ground. ${ }^{14}$ In our hospital it was shown in a retrospective study that after thoracotomy young children received lower daily morphine doses per body weight for a shorter time than older children. ${ }^{15}$

The ehildren's assessiment of the pain relief differed from that of the nurse. Although the mean total dose of morphine was significantly less in the indomethacin group than in the placebo group the children regarded their analgesia better. There were seven children in the indomethacin group who assessed their analgesic therapy to be good although no additional morphine had been administered to them during the study period. Three of these children had had hemia operations, one correction of syndactyly and three orthopaedic operations. Interestingly, four children in the placebo group considered the therapy poor because of too frequent injections of morphine!

Most children are afraid of intramuscular injections because they consider them painful. This may result in poor postoperative analgesia if only intramuscularly administered analgesics are used. In the present study 
prophylactic indomethacin infusion supplemented with intramuscular morphine resulted in better analgesia than intramuscular morphine alone, as evaluated by the children. No important unwanted effects were seen in this series. There should be no hesitation to employ prophylactic indomethacin infusion in the management of postoperative pain in children who do not have contraindications for non-steroidal anti-inflammatory drugs. Further studies are needed to evaluate whether rectally administered non-steroidal anti-inflammatory drugs are as effective as continuous infusion of indomethacin.

\section{Acknowledgements}

We wish to thank Dumex Ltd., Denmark, for providing the study drug and an IVAC-perfusor for our use. We extend our special thanks to Eva Ahlström-Bengs, M.Sc., for the encouragement and excellent cooperation in all stages of this work. Without the interest and cooperation of the nurses in the Recovery Room and on the surgical wards of The Children's Hospital, University of Helsinki, this study would not have been possible.

\section{References}

I Beyer JE, DeGood DE. Ashley LC. Russel GA. Patterns of pastoperative analgesic use with adults and children following cardiac surgery. Pain 1983; 17: 71-81.

2 Schechter NL, Allen DA, Hanson $K$. Status of pediatric pain control: a comparison of hospital analgesic usage in children and adults. Pediutrics 1986; 77: 11-15.

3 Stoddard FJ. Coping with pain: a developmental approach to the treatment of burned children. Am J Psychiatry $1982 ; 139: 736-40$.

4 Matker $L$, Mackie $J$. The incidence of postoperative pain in children. Pain 1983; 15: 271-82.

5 Mattila MAK, Ahlström-Bengs E, Pekkola P. Intravenous indomethacin or oxycocone in prevention of postoperative pain. Br Med J 1983; 287; 1026-9.

6 Sherry $D D$, Patterson $M W H$, Petry $R E$. The use of indomethacin in the treatment of pericarditis in childhood. I Pediatr 1982; 100: 995-8.

7 Smith IJ, Goss 1, Congdon PJ. Intravenous indomethacin for patent ductus arteriosus. Arch Dis Child 1984; 59 . $537-41$

8 Thalji AA, Carr I, Yeh TF, Raval D, Luken JA, Pildes RS. Pharmacokinetics of intravenously administered indomethacin in premature infants. J Pediatr 1980; 97: 995-1000.

9 Maunuksela E-L, Olkkola KT. Korpela R. Intravenous indomethacin as postoperative analgesic in children: acute effects on blood pressure, heart rale, body temperature and bleeding. Ann Clin Res 1987; 19; 359-63,

10 Maunuksela E-L, Olkkola KT, Korpela R. Measurement of pain in children with self-reporting and with behavioral assessment. Clin Pharmacol Ther 1987; 42: 137-41.
11 McGralh PJ, Curningham S'J, Goodman JT, Unruh A. The clinical measurement of pain in children: a review. Clin J Pain 1986; 1: 221-7.

12 Maumuksela E-L, Korpela R, Oikkola KT. Double-blind multiple dose comparison of buprenorphine and morphine in postoperative pain of children. Br J Anaesth 1988; 60: 48-53.

13 Owen $H$, Glavin JR, Shaw NA. Ibuprofen in the management of postoperative pain. Вс J Antesth 1986; 58: 1371-5.

14 Burokas $L$. Factors affecting nurses' decisions to medicate pediatric patients after surgery. Heart Lung 1985; 14 : 373-9.

15 Matunksela E-L, Suutarinen T. Besonderheiten der Schmerzbebandlung im Kindesalter. Anästhesie \& Intensivmedizin (in press).

\section{Résumé}

L'efficacié prophylactique d'une perfusion d'indométhacine comme analgésique en période post-opératoire a été étudiée chez 100 enfants agés de là 16 ans. A la fin de la chirurgie un

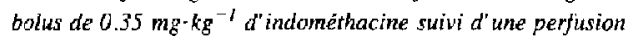
de $0.07 \mathrm{mg} \cdot \mathrm{kg}^{-1}$ pour 24 heures ou du placebo a été administré à clouble insu. L'efficacité du traitement a été mesurée par la nécessité d' ajouter de la morphine administrée par voie intraveineuse à des doses de $0.1 \mathrm{mg} \cdot \mathrm{kg}^{-1}$ à la salle de réveil et 0.15 $m g \cdot \mathrm{kg}^{-1}$ par voie intramasculaire stor les étages selon les besoins. D'autres mesures d'efficacité étaient l'évaluation de l'intensité de la douleur en salle de réveil et le soulagement sur les étages. En salle de réveil les scores de douleur étaient différents entre les groupes avantageans l'indométhacine uniquement à 30 minutes $(p<0.05)$ mais le besoin de morphine était significativement moindre $(p<0.01)$ dans le groupe indométhacine. Sur les étages les doses moyernes de morphine adminis. trées et les scores de douleur notés par l'infirmière n'étaient pas différents entre les groupes de l'étude. Cependant dans le groupe indométhacine la dose totale de morphine donnée pendant 24 hewres érait plus basse ( $p=0.02$ ) et les enfanis ont évalué le soulagement de la douleur comme étan significative. ment meilleur $(p<0.02$ ). Vingt pour cent des enfants dans les deux groupes ont démontré des nausées transitoires ainsi que des vomissements. Aucune réaction cutanée ou autres manifestations allergiques n'étaient observées. La perfusion prophylactique d'indométhacinte a dinthue le besoin de morphine et a provoqué une meilleure anaigésie postopératoire que la morphine seule p.r.n. 